\title{
Efficacy of Integrative Behavioural Couples Therapy and Cognitive Behavioural Therapy in Reducing Conflict and Violence-Related Marital Distress
}

\author{
Stephen Doh Fia, PhD \\ University of Cape Coast, Department of Guidance and Counselling, Ghana \\ Doi:10.19044/esj.2020.v16n20p66 \\ URL:http://dx.doi.org/10.19044/esj.2020.v16n20p66
}

\begin{abstract}
This study investigated the ability of Integrative Behavioural Couples Therapy and Cognitive Behavioural Therapy in reducing conflict-related and violence-related marital distress among couples in the Church of Pentecost in the Cape Coast Metropolis in the Central Region of Ghana. The researcher employed a quantitative research method, using a pre-test, post-test control group, a kind of quasi-experimental research design. The researcher selected 60 respondents who were severely distressed out of 215 married couples using a compendium of instruments on Conceptualising and Measuring "Healthy Marriages" for Empirical Research and Evaluation Studies (Task One Part II). Participants were put into three groups of 10 couples each, two for the treatment groups and the third one for the control group. The data were analysed using means, standard deviations and two-way mixed ANOVA. The results showed that both therapies reduced conflict-related and violencerelated marital distress. However, Integrative Behavioural Couples Therapy was more effective than Cognitive Behavioural Therapy.
\end{abstract}

Keywords: Integrative Behavioural Couples Therapy (IBCT), Cognitive Behavioural Therapy (CBT), Conflict-related marital distress, Violencerelated marital distress

\section{Introduction}

The definition of marriage varies according to different cultures. In some cultures, marriage is recommended or considered to be compulsory before pursuing any sexual activity. When defined broadly, marriage is considered culturally universal. According to Haviland, Prins, McBride and Walrath (2011), marriage, also called "matrimony" or "wedlock," is a socially or ritually recognised union or legal contract between spouses that establishes rights and obligations between them and their children, and between them and their in-laws, as well as society in general. Marriage is therefore seen as a form 
of a relationship that is not limited to the couples only but also the entire family of the married couples. However, Macdonald (1977) is of a contrary view as he sees marriage as "the ceremony, act, or contract by which a man and a woman become husband and wife" (p.25). Hubpages (2016) however, rejects Macdonald (1977)'s stance by stating that marriage is "the approved social pattern whereby two to more persons established a family".

As two people from completely different homes with diverse upbringing come together, there is bound to be disagreements. While some may communicate effectively and agree to disagree or come to a common understanding, others are likely to dwell in their thoughts and continue to argue out their points fruitlessly. This situation is evident in marriages all around us; from that of our parents, neighbours and others. Some of us recall childhood memories of having to isolate ourselves and use earplugs just to eliminate the noise from arguments between our parents, or walking out of the house so we can avoid the scene completely. All these were signs of our parents or guardians experiencing marital distress. Though no form of distress is healthy, we can confidently say those involving mere arguments were better to witness than the ones which involved physical assault.

The prevalence of conflict and violence in marriages cannot be understated. Marital violence can have a major impact on the relationship, psychological, as well as the physical well-being of each spouse. Amuzu (1997) observed that women sustain injuries as a result of marital violence which includes cuts, broken bones, concussions, miscarriages, as well as permanent injuries such as damage to joints, partial loss of hearing or vision, scars from burns, knife wounds and even death. Statistics in Ghana show that between January 1999 and December 2002, the Women and Juvenile Unit of the Ghana Police Service (WAJU) recorded 1,869 cases of assault/wife battering in the nation's capital Accra, WAJU(as cited in Amoakohene 2004). When a man is faced with challenges such as bad economic conditions, low wages, poor working conditions and unemployment, it can lead to the man being desperate which is likely to lead to violence at home, UNR (as cited in Ackah 2012).

Some studies have found that children, who are exposed to marital distress, particularly to violence at home, are at greater risk for their emotional problems. This implies that children from distressed couples are likely to experience distress in their future relationships (Association for Advancement of Behaviour Therapy, 2014).

A study by Morrison, Coiro and Blumenthaf (1994) also indicated that family conflict is key among the pre-disruption factors that affect the wellbeing of children. Indeed, some researchers have shown that parental discord can be more disruptive to children than divorce or the loss of a father (Grych \& Fincham, 1990). Children living in high conflict two-parent families 
manifest more social, emotional, and behavioural problems than children living in single-parent families with minimal conflict. This clearly shows that not only parents suffer from the effects of conflict and violence-related marriages but also the offsprings of such relationships.

According to Fischer and Fink (2014), distressed couples have been found to exhibit more negative affect, such as criticism, defensiveness, contempt, stonewalling, and belligerence, in dyadic interactions, and show more rapid and longer-lasting hostility responses. Gottman \& Notarius (as cited in Fischer and Fink, 2014) observed that distressed couples also frequently fail at repairing conflict and begin to introduce the idea of schema restructuring.

According to Fincham (2003), spouses' report of conflict over extramarital sex, problematic drinking, or drug use predict divorce, as do wives' reports of husbands being jealous and spending money foolishly.

In an attempt to explore viable ways of reducing the prevalence of conflict and violence-related marital distress for the benefit of both couples and the children involved, Cognitive Behavioural Therapy and Integrative Behavioural Couples Therapy were introduced to the selected respondents.

According to Halford (2011), Cognitive Behaviour Therapy (CBT) is a simple idea that our unique patterns of thinking, feeling, and behaving are significant factors in our experiences, both good and bad. Since these patterns have such a significant impact on our experiences, it follows that altering these patterns can change our experiences. CBT therefore aims to change our thought patterns, the beliefs we may or may not know we hold, our attitudes, and ultimately our behaviour in order to help us face our difficulties and more effectively strive towards our goals. However, IBCT focuses on increasing emotional acceptance, as well as direct change, in partners. IBCT assumes that relationship problems result not just from the egregious actions and inactions of partners but also in their emotional reactivity to those behaviours. Therefore, IBCT focuses on the emotional context between partners and strives to achieve greater acceptance and intimacy between partners as well as make deliberate changes in target problems (Hayes, 2004).

The goals of CBT include providing symptom relief, assisting clients in resolving their most pressing problems, and teaching clients some relapse prevention strategies. Another goal is to change the way clients think by using automatic beliefs to reach the core schemata. The goals of Integrative Behavioural Couples Therapy is "integrative" in at least two senses: First, it integrates the twin goals of acceptance and change as positive outcomes for couples in therapy. Couples who succeed in therapy usually make some concrete changes to accommodate the needs of the other but they also show greater emotional acceptance of the other. Second, IBCT integrates a variety of treatment strategies under a consistent behavioural theoretical framework. 
It is considered a third-generation behaviour therapy or sometimes called clinical behaviour analysis. Another element that defines IBCT is that it integrates strategies promoting changes with methods for fostering acceptance and tolerance (Jacobson \& Christensen, 1998). The findings of the extensive literature on marital conflict can be summarized in terms of a simple ratio: The ratio of agreements to disagreements is greater than 1 for happy couples and less than 1 for unhappy couples (Fincham, 2003).

\section{Purpose of the Study:}

The main purpose of this study was to determine the effectiveness of Integrated Behavioural Couples Therapy (IBCT) and Cognitive Behavioural Therapy (CBT) in reducing conflict-related and violence-related marital distress.

Many marriages, however, are saddled with numerous problems that threaten the survival of the relationship (Olayinka, 1990). Many couples suffering from distress in their relationships are frustrated, dissatisfied, disappointed and often regret being married (Neubeck \& Neubeck, 1997). These problems or challenges have led to the separation and divorce of many couples. Although most of these marriages were contracted religiously, divorce and separation became the end product. This has led to an increase in the divorce rate of marriages in the country (College Press, Ghana Web, 2016).

The Greater Accra Head Office of Legal Aid Ghana, recorded interesting statistics that at least $40 \%$ of marriages registered annually in the Region break up within a spate of 14 months. According to the Head of Registry of Legal Aid, the number of females who apply for a separation every week far outweighs that of their male counterparts (College Press, Ghana Web, 2016). Reports from the Accra Metropolitan Assembly (AMA) indicated that a total of 4,080 divorce cases were recorded in Accra alone from 1998 to 2016. According to the Accra Metropolitan Assembly, the marriages divorced were mainly customary ones and occurred between 2006 and 2013. Only the law courts have records of divorce concerning ordinance marriage while the AMA keeps records of customary marriages and divorces. Ghana Statistical Service reported that nearly 600,000 marriages contracted in Ghana have collapsed, more than three times the divorce cases of England and Wales put together in 2012 (College Press, Ghana Web, 2016). All these might be due to unresolved marital conflicts, violence or other difficulties causing distress in the marriages.

\section{Research Hypotheses}

1. $\mathrm{H}_{0}$ : There is no statistically significant difference in the effects of the interventions (CBT and IBCT) on conflict and violence related marital distress between the experimental and control group. 
$\mathrm{H}_{1}$ : There is a statistically significant difference in the effects of the interventions (CBT and IBCT) on conflict and violence related marital distress between the experimental and control group.

2. $\mathrm{H}_{0}$ : There is no statistically significant difference in the effectiveness of IBCT in reducing conflict and violence related marital distress as compared to CBT.

$\mathrm{H}_{1:}$ There is a statistically significant difference in the effectiveness of IBCT in reducing conflict and violence related marital distress as compared to CBT.

\section{Methodology}

The study made use of the pre-test, post-test control group, a type of quasi-experimental research design. The criterion used for respondent selection included being legally married, aged between 21 to 60 years and having scores between 366-600 on a marital distress scale. Quasi-experimental designs typically allow the researcher to control the assignment to the treatment condition, by using some criterion other than random assignment (Dinardo, 2008). The participants were assigned systematically to create three equivalent groups. Scores retrived from the marital distress scale of the 30 couples were ranked from the highest to lowest. The first three highest scores were assigned to a group each as 1(CBT), 2(IBCT) and 3(CONTROL). The next three were assigned as 1(IBCT), 2(CONTROL) and 3(CBT) in a like manner. It is pertinent to know that couples were ranked as a pair based on the partner with the highest score on the marital distress scale.

Figure 1: presents a pictorial illustration of the quasi-experimental method.

\begin{tabular}{|llcc|}
\hline G1 & 01 & X & 02 \\
G2 & 03 & X & 04 \\
G3 & 05 & - & 06 \\
\hline
\end{tabular}

Figure 1- Illustration of Quasi-Experimental Design

Adapted from Awabil et al. (2013)

\section{Interpretations}

G1 stands for Treatment group 1 (CBT Counselling)

G2 stands for Treatment group 2 (IBCT Counselling)

G3 stands for Control group

O1 stands for Pretest (CBT Counselling)

O2 stands for Posttest (CBT Counselling)

$\mathrm{X}$ stands for Treatment

O3 stands for Pretest (IBCT Counselling)

O4 stands for Posttest (IBCT Counselling)

O5 stands for Pretest (Control Group)

- $\quad$ stands for No Treatment (Control Group)

O6 stands for Posttest (Control Group) 
The instrument was administered and 60 respondents who were severely distressed according to a compendium of adapted instruments on Conceptualising and Measuring "Healthy Marriages" for Empirical Research and Evaluation Studies (Carrano, Cleveland, Bronte-Tinkew,\& Moore, 2003) as a screening tool (Task One Part II) were purposively selected. Twenty (20) of the respondents were taken through Integrative Behavioural Couple's Therapy after pretest of the instrument. Another group of twenty respondents were taken through Cognitive behavioural therapy while the last group of twenty (20) respondents were used as the control group.

The research instrument contained sections on Relationship/Marital Conflict and Relationship/Marital Violence. The items were measured using a five-point Likert scale. For marital conflict, the Likert type scale ranged as 1never, 2-rarely, 3-occasionally, 4-frequently and 5-very frequently. For marital conflict, the scale ranged as 1-very rarely, 2-rarely, 3-some of the time, 4-most of the time and 5-all of the time. The items on the instrument were 40, 20 under each dimension. Scoring of the sections ranged from 20-100 with the breakdown being: 20-40 (low), 41-60 (moderate), 61-80 (severe) and 81-100 (very severe). However, items 7 and 20 on marital conflict were reverse scored. The reliability of the original marital conflict and marital violence instrument was .951 and .830 respectively. After it was adapted from the reliability coefficients became .930 and .969 respectively, revealing the existence of internal consistency.

The intervention for the experimental group going through Cognitive Behavioural Therapy was in three sessions. Each of the CBT intervention session lasted for three hours. After the first session, cognitive restructuring and the processes involved in cognitive restructurings such as thought stopping, positive self-talk and visualization were all discussed with the participants. Issues about de-indoctrination and re-indoctrination were also discussed. The group members asked a series of questions that were discussed by the whole group. In the second session, the group proceeded to discuss what causes conflicts in marriage in general and how these conflicts could lead to marital distress. This was followed up by discussing the instrument which is on the causes of marital conflict. The group finally discussed how to avoid marital conflict using CBT skills and techniques.

It was very interactive as every member contributed to the discussions.

During the third session, the group then opened discussion on the causes of violence in marriage and how violence could lead to marital distress. The instrument on marital violence was discussed and some of the members shared their experiences on violence. The group finally discussed how to avoid violence in marriage using the skills and techniques of CBT.

Intervention for the experimental group on IBCT also comprised of three sessions; introductory, marital conflict and marital violence. For the first 
session, the counsellor gave an overview of what marital distress entails, the causes and effects of marital distress, what IBCT is all about and how it could help in reducing marital distress. Finally, the participants were taken through what group counselling entails and the need to treat the issue discussed confidentially. During the second session, employing IBCT strategies, Counsellor made use of brainstorming, self-examination and skills training to get participants to open up and discuss issues of conflict in their marriages. In the third session, participants discussed the instrument on violence and how violence could lead to marital distress. A further discussion was on how IBCT skills and techniques could help in reducing violence-related marital distress. Issues of problem solving, acceptance and tolerance which are key concepts of IBCT were also discussed. Also, each of the IBCT intervention session lasted for three hours.

Means, standard deviations and two-way mixed ANOVA were used in analysing the data because they possessed suitable characteristics considering the nature of the research. The test involved both within-subjects and betweensubjects measures (Mordkoff, 2016) making it advisable to use for this research. The F-statistics for the interaction between the treatment and the pretest-posttest factor in the test represents the main effect in this test and is a sound way to analyze pretest-posttest data (Dimitrov \& Rumrill, 2003; Mordkoff, 2016).

\section{Findings}

Table 1: Levene's Test of Equality of Error Variances

\begin{tabular}{lllll}
\hline & F & df1 & df2 & Sig. \\
\hline Dif_Conflict & 1.445 & 2 & 57 & .244 \\
Dif_Violence & 1.090 & 2 & 57 & .343 \\
\hline
\end{tabular}

The Levene's test in Table 1 showed that the error variance was equivalent or equal across the groups. 
Table 2: Test of between effects for differences among experimental conditions

\begin{tabular}{llllllll}
\hline \hline Source & $\begin{array}{l}\text { Dependent } \\
\text { Variable }\end{array}$ & $\begin{array}{l}\text { Type III Sum } \\
\text { of Squares }\end{array}$ & Df & Mean Square & F & Sig. & $\begin{array}{l}\text { Partial } \\
\text { Eta Sqr }\end{array}$ \\
\hline \hline \multirow{2}{*}{ Intercept } & Dif_Cnflict & 14168.067 & 1 & 14168.07 & 202.76 & .000 & .781 \\
& Dif_Violence & 21131.267 & 1 & 21131.27 & 989.47 & .000 & .946 \\
\multirow{3}{*}{ Group } & Dif_Cnflict & 5905.033 & 2 & 2952.52 & 42.25 & .000 & .597 \\
& Dif_Violence & 12215.433 & 2 & 6107.72 & 285.99 & .000 & .909 \\
& Dif_Cnflict & 3982.900 & 57 & 69.875 & & & \\
\multirow{2}{*}{ Total } & Dif_Violence & 1217.300 & 57 & 21.356 & & & \\
& Dif_Cnflict & 24056.000 & 60 & & & & \\
& Dif_Violence & 34564.000 & 60 & & & & \\
\hline \hline
\end{tabular}

From Table 2, the test of between-subject effects showed that there were significant differences among the experimental groups and the control groups across the dimensions. The post-test scores were significantly lower than the pre-test scores across both dimensions. This means that the intervention was generally effective.

Table 3: Means and Standard Deviations of the Dimensions of Marital Distress

\begin{tabular}{llllll}
\hline & Group & Pretest post-test & Mean & Std. Dev & N \\
\hline \multirow{5}{*}{ Marital conflict } & \multirow{2}{*}{ CBT } & Pre-test & 59.05 & 9.15 & 20 \\
& \multirow{2}{*}{ IBCT } & Post-test & 43.75 & 3.26 & 20 \\
\cline { 2 - 6 } & Pre-test & 62.25 & 8.24 & 20 \\
& \multirow{2}{*}{ CTRL } & Post-test & 34.70 & 2.79 & 20 \\
& \multirow{2}{*}{ Marital violence } & Pre-test & 57.65 & 5.92 & 20 \\
& \multirow{2}{*}{ CBT } & Post-test & 54.40 & 5.59 & 20 \\
\cline { 2 - 6 } & \multirow{2}{*}{ IBCT } & Pre-test & 60.15 & 4.17 & 20 \\
& & Post-test & 41.50 & 4.08 & 20 \\
\cline { 2 - 6 } & \multirow{2}{*}{ CTRL } & Pre-test & 60.70 & 2.59 & 20 \\
& \multirow{2}{*}{} & Post-test & 24.40 & 2.56 & 20 \\
& & Pre-test & 60.60 & 2.78 & 20 \\
& & Post-test & 59.25 & 3.37 & 20 \\
\hline
\end{tabular}

From Table 3, using means comparison of marital distress scores, the marital conflict levels of groups that were exposed to the IBCT ( $M=34.70$, $\mathrm{S}=2.79)$ were significantly lower than those exposed to CBT ( $\mathrm{M}=43.75$, $\mathrm{S}=3.26)$ and the control( $\mathrm{M}=54.40, \mathrm{~S}=5.59)$.

For marital violence, the mean score for the IBCT $(M=24.40, S=2.56)$ group was significantly lower than the CBT group ( $\mathrm{M}=41.50, \mathrm{~S}=4.08)$. The level of marital violence for the Control group (M=59.25, $S=3.37)$ was significantly higher than the CBT and IBCT groups. This means that the intervention with both CBT and IBCT had been effective in reducing marital conflict and violence-related distress among couples, with IBCT being more effective than CBT in helping Christian couples. 
Table 4: Pairwise Comparison of Experimental Conditions for Conflict and Violence Dimensions of Marital Distress

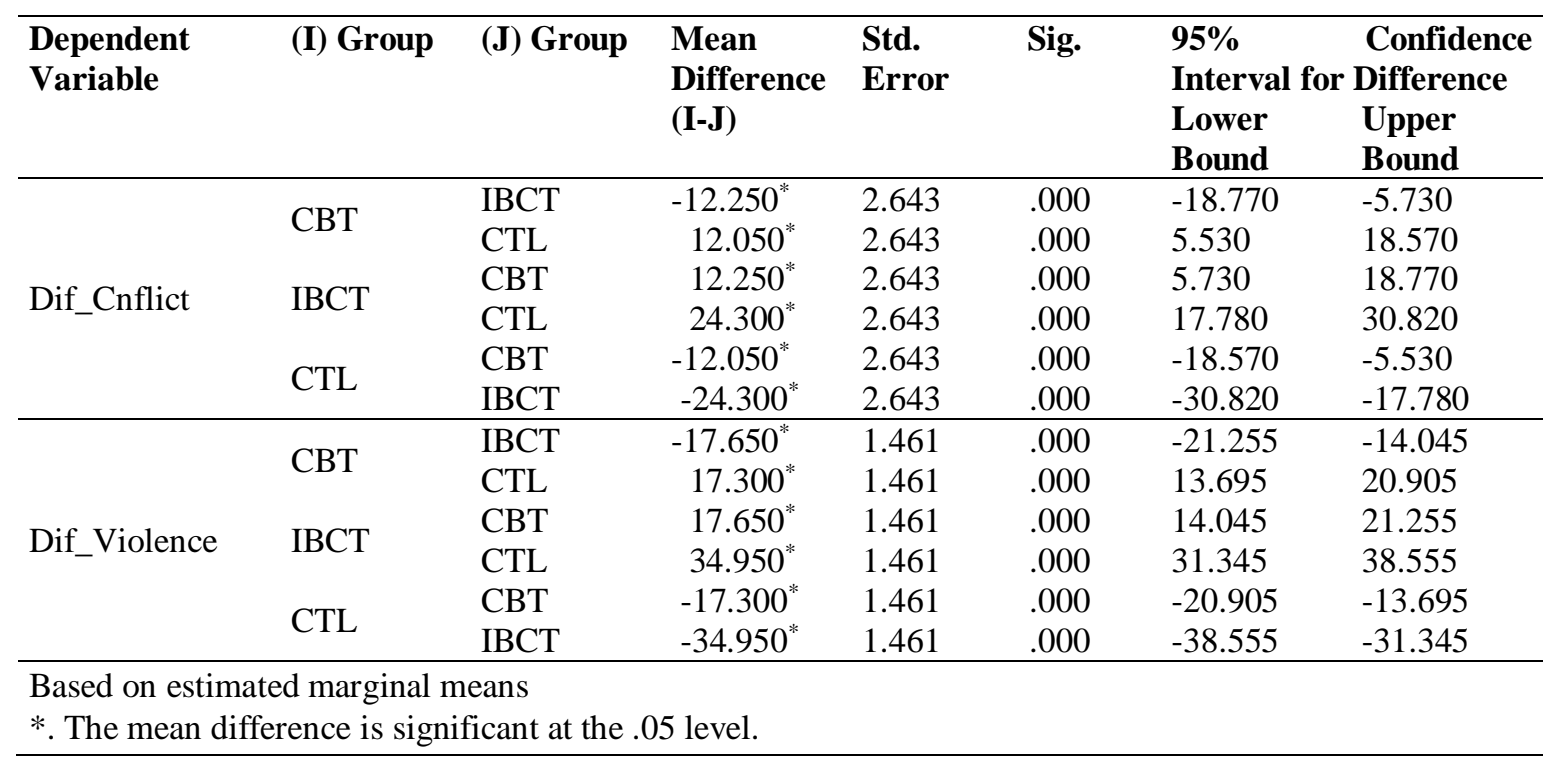

Table 4 shows marital distress scores for the groups that were exposed to the IBCT were significantly lower than those exposed to CBT and the control group for both dimensions. For marital conflict scores, the mean score for the IBCT group was significantly lower than the CBT group (mean difference $=12.25, \mathrm{p}=.000$ ). The level of marital conflict for the control group was significantly higher than the CBT group $(12.05, \mathrm{p}=.000)$ and IBCT $(24.30$, $\mathrm{p}=.000$ ). For marital violence, The level of marital violence for the control group was significantly higher than the CBT group (17.300, $\mathrm{p}=.000)$ and IBCT $(34.95, \mathrm{p}=.000)$.

This means that the intervention with both CBT and IBCT had been effective in reducing marital conflict and violence among couples, with IBCT being more effective than CBT in helping couples with conflict and violencerelated marital distress.

\section{Conclusion}

Results of the study indicated that both IBCT and CBT were effective in teaching couples techniques to reduce conflict and violence-related marital distress. However, it shows that techniques based on IBCT were more effective in reducing conflict-related and violence-related marital distress as compared to CBT among participants. Given this finding, it was concluded that conflict-related and violence-related distressed couples who were exposed to IBCT experienced a more effective reduction in marital distress as compared to participants who were exposed to the CBT. 
A study by Alhassan (1997) in Ghana showed that many marriages are best described as distressed. As the interventions (CBT and IBCT) were carried out on Ghanaian couples and has proven to be effective, it can be said that IBCT and CBT satisfy the cultural needs of Ghanaian Couples in reducing conflict-related and violence-related marital distress.

According to Mairal (2015) IBCT involves a balance between acceptance and change in the couple. Since conflict resolution involves the acceptance of differences and taking measures to address them, we can say that Mairal's assertion affirms the results of this study. Suarez (2014) also found in Mississippi, USA that marital quality was significantly improved using IBCT than CBT on disenchanted marriages. He found that the two treatment groups had improved significantly than those in the control. He explained that integrated therapy has the advantages of looking at all the problem areas of the client as compared to dwelling on the mental framework of the clients which the CBT possess. The assertion of Suarez may be deficient at a point in the sense that all challenges span from our mental processes. Myers (1998) believes that marital distress is a function of the mind which sees married people going through psychopathological tendencies which manifest in the behaviour of the spouses. To effectively deal with this psychopathology in marriage, the therapist needs to reorient the dissatisfied spouse and that implies working on the mind-set of the individual. This shows that the behaviour people demonstrate is an indication of their thought processes. This is why during therapy, the counsellor needs to assist couples to change their mental incongruities and replace them with positive thoughts that will be translated into acceptable behaviours. It can thus be said that studies by Suarez (2014) and Myers (1998) affirm the effectiveness of CBT and IBCT in reducing marital distress.

\section{References:}

1. Ackah, M.(2012). The Prevalence and Causes of Domestic Violence in the Yilo Krobo District. (Doctoral dissertation, University of Ghana).

2. Alhassan, Z. (1997, March 1). Why men are jealous. The Mirror, p. 11.

3. Amoakohene, M. I. (2004). Violence against women in Ghana: a look at women's perceptions and review of policy and social responses. Social Science \& Medicine, 59(11), 2373-2385.

4. Amuzu, M. (1997, April 10). Wife bashing: No reason, no justification. The Mirror, pp. 15-17.

5. Association for Advancement Behaviour Therapy. (2014). Marital distress. Retrieved 
fromhttps://utulsa.edu/wpcontent/uploads/2014/12/Marital-CoupleDistress.pdf

6. Awabil, G., Kolo, D. F., Bellow, M. R., Oliagba, A. D. (2013). Effects of study and self-reward skills counselling on study behaviour of university students in Ghana. The Counselor, 32(182), 39-46.

7. Carrano, J. Cleveland, K., Bronte-Tinkew, J., \& Moore, K. A. (2003).Conceptualizing and measuring healthy marriages for empirical research and evaluation studies: A compendium of measures. Washington, DC: Child Trends.

8. Chilemba, J. (2012). Effects of IBCT and CBT on dissatisfied married people in Tanzania. Journal of Social Psychology, 21(1), 83- 102.

9. College Press, Ghana Web. (2016). Over 4,000 coupes divorce. Accra, Ghana: Legal Aid.

10. Dimittrov, D. M.,\&Rumrill, P. D. (2003). Pretest-posttest design and measurement of change. Work, 20, 159-165.

11. Dinardo, J. (2008). Natural experiments and quasi-natural experiments. The New Palgrave Dictionary of Economics, 12(7), 856859.

12. Fincham, F. D. (2003). Marital conflict: Correlates, structure, and context. Current directions in psychological science, 12(1), 23-27.

13. Grych, J.H., \& Fincham, F. D. (1990). Marital conflict and children adjustment: A cognitive-contextual framework. Psychological Bulletin, 108(2), 267.

14. Halford, W. K. (2011). Marriage and relationship education. New York, NY: Guilford.

15. Haviland, W. A., Prins, H. E. L., McBride, B., \& Walrath, D. (2011). Cultural anthropology: The human challenge (13th Ed.). London: Cengage Learning.

16. Hayes, S. C. (2004). Acceptance and commitment therapy, relational frame theory, and third wave of behavioural and cognitive therapies. Behaviour Therapy, 35, 639-665.

17. Hubpages Inc. (2016). Concept of marriage. Retrieved http://hubpages.com/relat/

18. Jacobson, N. S., \& Christensen, A. (1998). Acceptance and change in couple therapy: A therapist's guide to transforming relationships. New York, NY: Norton.

19. Macdonald, D. L. (1977). The monk: A romance. Peterborough, ON: Broadview.

20. Mairal, J.B. (2015) 'Integrative behavioural couple therapy (IBCT) as a third-wave therapy', Psicothema, 27(1), pp. 13-18. doi: 10.7334/psicothema2014.101. 
21. Mensah, A. (2013). A comparison of cognitive behavioural therapy and integrative behavioural therapy in improving their marital satisfaction of dissatisfied couples. International Journal of marriage and family, 19(6), 1152-1169.

22. Mordkoff, J. T. (2016). Pre-test/post-test designs. Retrieved from https://explorable.com/pretest-posttest-designs

23. Morrison, D. R., Coiro, M. J., \& Blumenthaf, C. (1994, April). Marital disruption, conflict, and the wellbeing of children. In Annual meeting of the population association of America, USA (pp. 1-22).

24. Myers, O. (1998). Procedural and distributive justice effects moderated by organisational identification. Journal of Managerial Psychology, 20(1), 4-13.

25. Neubeck, K. J., \& Neubeck, M. A. (1997). Social problems: A critical approach. New York, NY: McGraw-Hill Companies.

26. Olayinka, M. S. (1990). Sex education and marital guidance. Lagos: Lantern Books.

27. Suarez, E. (2014). Impact of integrative behaviour couple therapy and cognitive behavioural therapy on older couples in Mississippi. Social Psychology Quarterly, 68(1), 80-102. 